Uluslararası Sosyal Bilgilerde Yeni Yaklaşımlar Dergisi,2020, 4(1), 1-16

International Journal of New Approaches in Social Studies, 2020, 4(1), 1-16

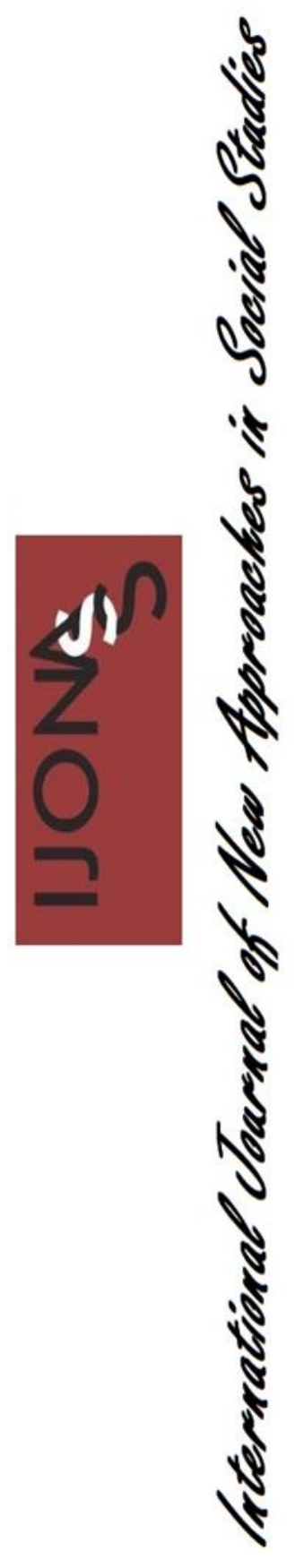

\title{
Sakarya Savaşı’nın Önemi ve Ders Kitaplarındaki Yeri Hakkında Sosyal Bilgiler Öğretmenlerinin Görüşleri
}

\author{
Cemal AVCI ${ }^{1}$, Hüseyin AÇIKALIN ${ }^{2 *} \&$ Turgut UĞURLU ${ }^{3}$
}

Gönderilme Tarihi:16 Kasım 2019

Kabul Tarihi: 03 Şubat 2020

DOI: $10.38015 /$ sbyy. 647634

\begin{abstract}
$\ddot{O} z:$
Tarih boyunca toplumların kaderini değiştiren önemli olaylar gerçekleşmişstir. İcatların, liderlerin ve Savaşların bazıları hem insanlı hem de milletler için olumlu ya da olumsuz büyük etki yapmışlardır. Türk tarihinde de böylesine önemli, yaşandiğl dönemi etkilediği gibi günümüzü de şekillendiren gelişmeler yaşanmıştır.

Bu çalışmada Türk milletinin kaderine etki eden 5 savaşstan bahsedilerek özellikle Sakarya Meydan Muharebesi ele alınmuştır. Sakarya Savaşı, Avrupalı devletlerin Türkleri Anadolu ve Balkanlardan çıarma faaliyeti olan Şark Meselesinde gerileyişimize son vermesi, Sevr Antlaşması'nı gerçekleş̧irmek isteyen İtilaf devletlerinin ve Yunanistan'ın faaliyetlerinin başarısız olacăğn ispat etmesi, Millî mücadele hareketinin başarll olacağına inancl perçinlemesi, Mustafa Kemal'in liderliğini içte ve dışta tartışmasız kabul ettirmesi ve uluslararası etkileri ile önemli bir dönüm noktasidır.

Böyle önemli olayların eğitimde hak ettiği yeri bulması gerektiği gerçeğinden hareketle çalısmamızda Sakarya Savaşı'nın "8. Sinıf Türkiye Cumhuriyeti İnklâp Tarihi ve Atatürkçülük Dersi Programı"nda aldı̆̆ yer ile Sakarya Savaşı'nın ögretimi hakkinda ögretmenlerin hazır bulunuşluk düzeylerini ve görüsslerini de tespit etmeye gayret edilmiştir.
\end{abstract}

Anahtar Kelimeler: Sakarya Savaşı, Liderlik, İnkılap Tarihi, Ders Programı.

\begin{abstract}
:
Important events that have changed the fate of societies exist throughout the history. Some of the inventions, leaders, and wars have had a great positive or a negative impact on both humanity and nations. Similarly, in Turkish history there exist important developments that have influenced the period these developments occurred and additionally shaped the present day.

In this study, the five wars that affected the fate of the Turkish nation are addressed and the Battle of Sakarya is discussed in details. The Battle of Sakarya, which had international outcomes as well, is a milestone in turkish history for ceasing the influence of the European states in the Eastern Question that involves the activities to expel the Turks from Anatolia and the Balkans, proving the failure of the activities of the Entente States together with Greece in the enforcement of the Treaty of Sevres, solidifying the belief that the Turkish National Movement would succeed eventually and the acceptance of the indisputable leadership of Mustafa Kemal both on national and international scale.
\end{abstract}

\footnotetext{
${ }^{1}$ Bolu Abant İzzet Baysal Üniversitesi, Türkiye. Orcid ID: 0000-0001-7357-0790

${ }^{2}$ Bolu Abant İzzet Baysal Üniversitesi, Türkiye. Orcid ID: 0000-0002-0959-0217

${ }^{3}$ Bolu Abant İzzet Baysal Üniversitesi, Türkiye. Orcid ID: 0000-0002-0826-1876

*Sorumlu Yazar (Corresponding Author): dualist25@hotmail.com
} 
Based on the fact that important topics such as the Battle of Sakarya should find their rightful place in history education and be discussed more rigorously, we examined how the topic of the Battle of Sakarya has been covered in the "syllabus of the course Turkish Republic Revolution History and Kemalism for 8th grade" and try to identify the readiness level of the teachers in the class when they discussed the topic together with their point of views on the topic.

Keywords: The Battle of Sakarya, Leadership, History of Turkish Revolution, Curriculum.

\section{GíRIŞ}

Türk çocuğu ecdadını tanıdıkça, daha büyük işler yapmak için kendinde kuvvet bulacaktır.

Mustafa Kemal Atatürk (Kocatürk, 1999, s. 175).

Tarih boyunca savaşlar, toplumların yaşantılarına önemli etkiler yapmıştır. Bazı savaşlar ise; toplumların kaderini değiştirmiş, yeni senaryolar ortaya çıkarmış ve önceden tasarlanan hamleleri baştan başa değiştirmiş, yeni lider ve kahramanların ortaya çıkmasına zemin hazırlayarak tarihte belirleyici rol oynamıştır.

Türklerin İslamiyet'i kabul etme sürecini başlatan Talas Savaşı, Selçuklu Devleti'nin temelini atan Dandanakan Savaşı, Anadolu'nun kapısını Türklere açan Malazgirt Meydan Savaşı, Çağ açıp çağ kapatan İstanbul'un Fethi ve I. Dünya Savaşı'nın seyrini önemli ölçüde etkileyen Çanakkale Cephesi gibi savaşlar Türk tarihi açısından dönüm noktalarıdır.

Tarihi ve kökleri Milattan öncesine dayanan Türk milletinin büyük kahramanlıklar göstererek elde ettiği zaferlerden biri de Sakarya Meydan Muharebesi'dir. Sakarya Meydan Muharebesi'nin kazanılması Kurtuluş Savaşı'nın dönüm noktası olmuştur. 'Hatta denilebilir ki Sakarya, yalnız Kurtuluş Savaşı'nın değil 300 yıldır süregelen bir çözülüşün de dönüm noktasını belirleyen bir ağırlıktadır” (Artuç, 1985, s. 6).

Böyle önemli ve topyekûn mücadele ile kazanılan savaşlar milletlerin birlik ve beraberlik duygusunun gelişmesine önemli katkılar sağlayabilmektedir. Bu nedenle Sakarya Meydan Muharebesi, Türk ve Türkiye tarihinde yapmış olduğu etkiler nedeniyle birlik ve beraberliğin sağlanması yönünden katkılarda bulunabilecek bir potansiyele sahiptir. Bu konuda medya organları ve diğer propaganda yöntemleri kullanılarak çalışmalar yapılabileceği gibi en önemli faaliyet yolu eğitim-öğretim alanı olmalıdır düşüncesi ile çalışmamızda Sakarya Meydan Muharebesi'nin önemi, eğitimde yer alış şekli, birlik ve beraberliğe nasıl katkı yapılabileceği konusunda tespitlere ulaşmaya çalışılmıştır.

\section{TÜRK MILLETINİN KADERİNI DEĞISTTIREN SAVAŞLAR}

Savaşların milletler üzerinde sosyal, siyasi, ekonomik ve psikolojik gibi bir çok alanda etkisi vardır. Kısaca savaşlar tarihin akışına yön vermişlerdir. Alan yazını ve literatür incelendiğinde insanlık tarihine etki eden bir çok savaş yaşandığı görülmektedir. Biz ise bu çalışmamızda Türk tarihine etki eden 5 savaştan kısaca bahsederek özellikle Sakarya Meydan Muharebesi'nin önemi üzerine çalışma yaptık.

751 yılında Çinliler ile Abbasiler arasında yaşanan Talas Savaşı’nın, Türk-İslam dünyası üzerinde büyük etkileri olmuştur. Bu savaşa kadar farklı dinleri benimsemiş olan Türkler, Talas Savaşı ile birlikte önceleri boylar halinde İslamiyet'i kabul etmeye başlamış daha sonra ise 
İslamiyet Türkler arasında en yaygın din haline gelmiştir. Türkler sadece İslamiyet'i benimsemekle kalmamış, aynı zamanda İslamiyet'in en büyük koruyucusu olmuştur. Talas Savaşı ile başlayan gelişme Türk-İslam tarihinin bir dönüm noktası olmuştur.

1040 yılında Selçuklular ile Gazneliler arasında yapılan Dandanakan Savaşı sonucunda Gazneliler yıkılma sürecine girerken, Selçuklular ise büyük bir zafer elde etmiştir. "Böylece Selçuklular, Cend şehrinden ayrıldıktan sonra girdikleri İslam aleminde Karahanlı ve Gazneliler ile giriştikleri uzun süreli çetin mücadelelerin zirvesini oluşturan Dandanakan Zaferi'nden sonra bağımsızlığını kazandılar (Tekinoğlu, 2015, s. 78). Dandankan Savaşı ile başlayan gelişme ise; Büyük Selçuklu, Anadolu Selçuklu, Osmanlı Devleti ve Türkiye Cumhuriyeti'ne kadar gelen bir sürecin yaşanmasını sağlamıştır.

1071 yılında Selçuklular ile Bizans arasında yaşanan Malazgirt Meydan Muharebesi'nin amacı, Selçuklular için yeni bir yurt edinme arayışı iken Bizans açısından da Türklerin ve Müslümanların Anadolu'ya girişini engellemekti. Sultan Alparslan komutasındaki Selçuklu ordusu, Bizans'a karşı büyük bir zafer elde etmiştir. "Bu büyük zafer yalnız İslam dünyasında değil, Bizans ve Avrupa ülkelerinde de dikkatle takip edildi. Zaferden birkaç yıl gibi çok kısa süre sonra Anadolu ve Suriye' de hakimiyetin Türklerin eline geçmesi sonucunda, bütün Avrupa Bizans'1 kurtarmak gayesiyle harekete geçecek ve Haçlı Seferlerinin hazırlıklarına başlayacaktır" (Tekinoğlu, 2015, s. 158). Malazgirt Meydan Muharebesi, Anadolu'nun bir Türk yurdu olmasını sağlayan sürecin temelleri atmıştır.

1453 yılında İstanbul'un Fethi ile başlayan süreç sadece Türk tarihi açısından değil dünya tarihi açısından da önemli sonuçları beraberinde getirmiştir. Şöyle ki; Fatih Sultan Mehmet "Batı'ya meydan okuyarak iki ülkeyle iki denizin: Rumeli ile Anadolu'nun, Akdeniz'le Karadeniz'in hükümdarı oluyordu (Kinross, 2008, s. 110). Böylece hem İslam dünyası hem de Batı dünyası karşısında Osmanlı Devleti’nin askeri ve moral üstünlüğü perçinlenmiş oldu.

I. Dünya Savaşı'nda vatan savunmasının sembolü niteliğinde olan ve savaştaki dengeleri önemli ölçüde etkileyip savaşın süresini uzatan Çanakkale Cephesi'nin şehit ve yaralı sayısı itibariyle Türk halkına uzun süreç içerisinde telafisi güç kayıplar vermesine rağmen Türk tarihinin seyri açısından büyük önemi vardır. "Çanakkale Savaşlarının olumlu neticeleri arasında Mustafa Kemal'i, Türk ve dünya kamuoyuna tanıtması ve daha sonra gerçekleşecek Milli Mücadele'de moral destek sağlamasını sayabiliriz" (Yalçın vd., 2000, s. 94). Çanakkale Savaşı'nı, Milli Mücadelenin gerçekleştirilmesi için gerekli şartları sağlayan ve Türkiye Cumhuriyeti'nin kuruluşuna ortam hazırlayan gelişmeleri kolaylaştırarak bir milletin kaderini değiştiren savaşlardan görmek gerekir.

\section{ŞARK MESELESİ VE OSMANLI IMPARATORLUĞU'NUN ÇÖKÜŞ SÜRECİ}

Avrupalı devletler, Türklerin önce Anadolu ve Balkanlara yerleşmesini önlemek istemiş ancak bu amaçlarına ulaşamayınca Türkleri, Anadolu ve Balkanlardan çıkarmayı amaçlamış ve bunu bir siyasi kavram olarak Şark Meselesi adıyla ilk kez Viyana Kongresi'nde telaffuz etmişlerdir. Oysa ilk kez Viyana Kongresi'nde dile getirilen Şark Meselesinin kökleri çok daha eskiye dayanmaktadir.

Şark Meselesini iki safhada ele almak mümkündür. Birinci safha 1071-1683 (Malazgirt ZaferiViyana Bozgunu) tarihleri arasında gerçekleştirilmiştir. Avrupa için birinci safhada Şark Meselesinin hedefi Hıristiyanlara meskun toprakların (Anadolu, Balkanlar vs.) Türkler 
tarafından fethini engellemekti (Hourıe, 2016, s. 12). Bu süreçte Avrupalılar, Türklerin Anadolu ve Balkanlara yerleşmesini önleyememiştir.

1683 yılından itibarense Şark Meselesinin ikinci safhası başlamıştır. Bu sefer Avrupalılar taarruzda, Türkler savunmadadır (Hour1e, 2016, s. 12-13).

1699'da Büyük Savaşta hemen bütün Hıristiyan alemi Papa'nın yardım çağrılarıyla ve teşvikiyle imparatorun etrafinda Türkler aleyhine toplanmış bulunuyordu (Akçura, 2016, s. 51). 1683 yılında başlayan ve 1699 yılında imzalanan Karlofça Antlaşması ile biten bu Büyük Savaşta, Avrupalı devletlerin Türklere karşı bir çatı altında toplandığını görmekteyiz. Karlofça Antlaşması ile birlikte Osmanlı Devleti, Avrupalılar karşısında ilk büyük toprak kaybını yaşamakta ve bu durum Avrupalıları artık eskisinden daha fazla cesaretlendirmekteydi.

Viyana Bozgunu'ndan başlayıp Karlofça Antlaşması ile hızlanan ve Sakarya Meydan Muharebesi'ne kadar gelişen süreçte Avrupalı devletlerin Türkleri, Balkanlar ve Anadolu'dan çıkarmak için büyük uğraşlar verdiğini görmekteyiz.

Özellikle I. Dünya Savaşı'nda Şark meselesindeki amaçlarına İtilaf Devletleri eliyle ulaşmaya çalıştıkları anlaşılmaktadır. "Osmanlı İmparatorluğu'nun bölünmesi ile ilgili antlaşmalar, Birinci Cihan Savaşı sırasında çeşitli devrelerde karşılıklı görüşmeler sonucu karara bağlanmış ve antlaşma konusu olmuştur" (Eroğlu, 1977, s. 49). Yaptıkları gizli antlaşmalar yoluyla Türkleri, Anadolu'dan atmak amacını yani Şark meselesini halletmeye çalışıyorlardı.

Yüzyıllar boyu Osmanlı Devleti içerisinde Türk toplumu ile uyum içerisinde yaşayan azınlıklar, milliyetçilik akımı ve Avrupalı devletlerin kendi emellerini gerçekleştirmek için yaptıkları kışkırtmaların etkisiyle Osmanlı Devleti'ne karşı cephe almışlardır. "Osmanlı Devleti içinde özellikle Ermeni ve Rum azınlık, Wilson prensiplerinden ve İtilaf Devletleri'nin sahte vaatlerinden yararlanarak Türk toplumu aleyhine harekete geçmişlerdi. 1918 sonu ile 1919 yılı başlarında hacimlerinden büyük toprak taleplerini 1srarlı bir şekilde başlatıyorlardı. Bunu yaparken de bulundukları ve istedikleri bölgenin demografik, etnik, politik, ekonomik ve diğer hukuki bakımlardan haklı gerekçelere dayanıp dayanmadıklarına hiç bakmıyorlardı" (Özsoy, 1999, s. 91).

Bilakis Avrupalı devletler, I. Dünya Savaşı'nın ardından imzalanan Mondros Mütarekesi ve Sevr Barış Antlaşması ile Şark meselesini hallettiklerini düşünüyorlardı. Ancak Türk milletinin Mustafa Kemal Atatürk öncülüğünde gerçekleştirdiği Milli Mücadele ve özellikle Sakarya Meydan Muharebesi, Şark meselesi projesini tarihe gömmüştür.

\section{MILLİ MÜCADELE HAREKETININ ORTAYA ÇIKIŞI VE SAKARYA SAVAŞI'NDA MUSTAFA KEMAL'IN LIDERLIK YÖNÜ}

“1335 (1919) senesi Mayısı’nın 19’uncu günü Samsun’a çıktım.”

Bu cümle, büyük nutkunun ilk ve başlangıç cümlesidir. Mustafa Kemal'in yeni hayatı, yeni alemi, onun 1919 Mayısı'nın 19'uncu günü Samsun kıyısında Anadolu karasına ayak basmasıyla başlar. Yani onun zuhurunun hem kendi kaderine hem milletimizin tarihine, hem çağımızın akışına çeşitli yönlerden yön ve şekil veren safhası o gün, orada ve Mustafa Kemal' in 
Samsun kıyısına ayak basmasıyla başlamıştır. Tek Adam, işte o günden sonra ve çıktığı bu yeni yolculukta zuhur edecektir (Aydemir, 2011, s. 372) ...

Mustafa Kemal Paşa, Samsun'dan sonra büyük davayı yürütmek için 25 Mayıs 1919'da Havza'ya hareket etmiştir. Kurtarıcı, milli lider ve ihtilalci Mustafa Kemal, Havza'dan verdiği emirlerle Anadolu'nun her tarafinda mitingler tertip ettirmekle işe başladı (Eroğlu, 1977, s. 84).

Artık mücadele şahsi olmaktan çıkıp milletin birlik ve dayanışmasını sağlamaya yönelik olmaliydı.

"Bütün baskılara karşın, 21/22 Haziran 1919 gecesi yayımladığı Amasya Tamimi'nde "Vatanın tamamiyeti, milletinin istiklali tehlikededir". "Milletin istiklalini, yine milletin azim ve kararı kurtaracaktır” ifadesiyle Kurtuluş Savaşı'nın başladığını ve artık idarenin millette olduğunu ilan etmiştir. Mustafa Kemal, Erzurum'da iken 8-9 Temmuz gecesi görevinden alındığını bildiren İstanbul Hükümeti ile yaptığı telgraf görüşmesinde resmi görevlerinden ve askerlik mesleğinden istifa ettiğini bildirmiştir. Böylece sine-i millete dönmüştür" (Avc1, 2013, s. 55).

Mustafa Kemal millet iradesinden aldığı güçle Erzurum Kongresi'ne katılmış, bu kongrede liderlik yönünü ön plana çıkararak manda ve himaye yanlısı olan delegelerin yoğun çabalarına rağmen tam bağımsızlığa aykırı olduğu için bu görüşün reddedilmesini sağlamış, Misak-1 Milli'nin temelini oluşturacak kararların alınmasında etkin rol oynamıştır.

Erzurum'dan sonra Sivas'a geçen Mustafa Kemal, ulusal nitelikli toplanan bu kongrede de ciddi bir muhalefete rağmen başkan seçilmiştir.

“Sivas Kongresi, Erzurum'da alınan kararları aynen benimsedi ve yurt ölçüsünde bir örgüt kurdu: Anadolu ve Rumeli Müdafaa-i Hukuk Cemiyeti. Erzurum'da olduğu gibi yönetim kurulu işleviyle, başkanı Mustafa Kemal olan bir Heyet-i Temsiliye oluşturuldu. ARMHC seçimleri yaptırtacak, seçimlerde ağırlığını koyacak ve Mebusan Meclisi'nin toplanmasını sağlayacaktı" (Akşin, 2019, s. 139).

Sivas Kongresi'nin etkisiyle Millî Mücadele düşmanı Damat Ferit Paşa Hükümeti istifa etmek durumunda kalmış, yerine Ali Rıza Paşa Hükümeti kurulmuştu.

Ali Rıza Paşa Hükümeti adına Salih Paşa ile yapılan Amasya Görüşmeleri sonucunda Osmanlı Mebusan Meclisi'nin açılması kararlaştırıldı. Mustafa Kemal, Mebusan Meclisi'nin İstanbul'da toplanmasına sıcak bakmamış ve Meclisin Anadolu'da toplanmasını istemiş̧i. Ancak bu isteği İstanbul Hükümeti tarafından kabul görmemiştir.

Temsil Heyeti daha güvenli olması, İstanbul'a ve Batı Cephesine yakın olması sebebiyle çalışmalarını daha etkin yürütebilmek için 27 Aralık 1919' da Ankara'ya gelmiş ve halkın sevgi gösterileriyle karşılanmıştı. Ankara'da yapılan toplantılarda Mustafa Kemal, Mebusan Meclisi'ne katılacak delegelerden Mecliste bir Müdafaa-i Hukuk grubunun kurulmasın1, kendisinin Mebusan Meclisi'ne başkan seçilmesini ve Milli Kongre kararlarının kabul edilmesini istemişti. Bu istekleri gerçekleştirme konusunda Mustafa Kemal'e söz veren mebuslar sadece Misak-1 Milli kararlarının kabul edilmesini sağlamış ancak diğer istekleri gerçekleştirme konusunda tutarlı ve cesur davranamamışlardır. 
12 Ocak 1920'de Padişahın beyannamesi okunarak açılan Mebusan Meclisi'ne Erzurum mebusu olarak seçilmesine rağmen güvenli olmadığ 1 için Mustafa Kemal katılmamıştır. 28 Ocak 1920'de Son Osmanlı Mebusan Meclisi'nde kabul edilen Misak-1 Milli kararları ile Mondros Mütarekesi'nden sonra yapılan tüm işgallere karşı çıkılarak sınırlar belirlenmiş, azınlıklar ile ilgili durum karar bağlanmış, boğazlarda sadece Türk egemenliğinin olması gerektiği kararlaştırılmış, kapitülasyonlara net bir şekilde karşı çıkılmış, Osmanlı' dan kalan borçların hangi şartlar altında ödeneceği belirtilmiş ve Batı Trakya, Kars, Ardahan, Batum ile Arap ülkelerinin geleceği konusunda gerekirse halkoyuna başvurulacağ Özetle "Misak-1 Milli demokratik-ulusçu hareketin dünyaya duyurulan programı olmuştur" (Akşin, 2019, s. 144).

Ancak Misak-1 Milli kararlarından rahatsızlık duyan İtilaf devletleri, gerçek yüzlerini göstererek 16 Mart 1920' de İstanbul'u resmen işgal etmiş, Mebusan Meclisi'ni dağıtmış ve bazı mebusları Malta adasına sürgüne göndermişlerdi. Yaşanan bu gelişmeler Ankara'da yeni bir meclisin açılmasını zorunlu hale getirmiş ayrıca Mustafa Kemal'in, Mebusan Meclisi'nin İstanbul'da toplanmaması gerektiği düşüncesinin haklılığ 1 ve bir lider olarak ileri görüşlülüğünün önemi bir kez daha ortaya çıkmıştır. Gelişmeler Anadolu hareketinin haklılığını ortaya çıkarmıştır.

"Büyük Millet Meclisi memleketin kara günler yaşadığı bir zamanda kuruldu. Çok zayıf kuvvetlerimiz, Batı ve Güney cephelerinde çarpışıyorlardı. Batılılar, Türkiye'yi parçalamaya çalışırken içteki karışıklıklar önem kazandı. En büyük tehlike Şeyhülislam Dürrizade Mehmet Efendi'ye, düşmanların etkisi ile hazırlatılan fetvalardan geliyordu" (Belen, 2014, s. 183). Gerek İtilaf devletleri gerekse İstanbul Hükümeti'nin kışkırtmaları sonucu Anadolu'nun birçok yerinde ayaklanmalar ortaya çıkmış, azınlıkların zararlı faaliyetleri ve saldırıları günden güne daha da artmıştı.

Büyük Millet Meclisi ayaklanmalara karşı birçok tedbir almış isyan bölgelerine Kuva-i Milliye birlikleri sevkedilmişti. "Büyük bir bunalım içinde işe başlayan ve çok farklı görüşleri içinde toplayan Büyük Millet Meclisi'nin en büyük dayanağı ve birlik kaynağı "İstiklal aşkı" idi. Bu aşk onu zafere ulaştıracaktır" (Belen, 2014, s. 194).

"Yurdun birçok yerini işgal etmiş olan İngiliz, Fransız, İtalyan, Yunan ve Ermeni kuvvetlerine karşı başlangıçta milli kuvvetlerle, daha sonra teşkilatlı ordu ile karşı konuldu; sonunda Yunanlılar hariç, diğerleri ile yapılan antlaşmalarla Doğu ve Güney Cephelerinde bir dereceye kadar emniyet ve sükûnet sağlanabildi ve Misak-1 Milli hudutlarına ulaşıldı" (Görgülü, 1993, s. 197).

Ancak Batı Cephesi'nde özellikle İngiliz destekli Yunanlılara karşı yapılan mücadele daha zorlu ve uzun süreli olacaktı. I. ve II. İnönü Muharebelerinde Yunanlılar yenilgiye uğratılmış ve bu askeri başarılar beraberinde siyasi başarıları da getirmişti. İtalyanlar Anadolu'dan çekilmeye başlarken, İnglizler Malta tutuklularının bir bölümünü serbest bırakmış, Fransızlar işgal ettikleri bazı bölgelerden çekilmiş, Mustafa Kemal ve Büyük Millet Meclisi'nin uluslararası alanda etkinliği artmıştı. 


\section{SAKARYA SAVAŞI VE ÖNEMI}

\section{Kütahya-Eskişehir Muharebeleri ve Sakarya Savaşı Öncesi Gelişmeler}

I. İnönü ve II. İnönü Muharebelerinde yenilgiye uğrayan Yunan kuvvetlerine İtilaf devletlerinin duyduğu güven iyice azalmıştı. Bu koşullar altında Yunan ordusu, İtilaf devletlerinin güvenini yeniden kazanmak, Ankara'yı ele geçirip TBMM'yi dağıtmak ve Sevr Antalaşması'nı yürürlüğe koymak amacıyla 10 Temmuz 1921'de bütün cephelerdeki kuvvetleriyle saldırıya geçti.

"Yunanlılar Eskişehir, Kütahya ve Afyon'u ele geçirdiler. Mustafa Kemal, ordunun Sakarya gerisine çekilmesini uygun gördü çünkü Yunan ordusu çok daha güçlüydü. TBMM'de panik ve kızgınlık havası esiyordu. Kayseri'ye doğru bir göç dalgası başlamıştı. Bir ara devlet dairelerinin de Kayseri’ye taşınması düşünüldü. Ordu 25 Temmuz'da Sakarya'nın doğusunda yerini aldı” (Akşin, 2019, s. 162).

Kütahya-Eskişehir Muharebelerinden sonra ortaya çıkan tablo Mustafa Kemal'in hem askeri hem de siyasi yönden öngörülerinin ne kadar doğru olduğunu ortaya çıkarmıştır. Çünkü ordumuzun Sakarya Irmağı'nın doğusuna çekilmesi ile Türk ordusunun daha az yıpranması sağlanırken, Yunan ordusunun da hareket üssünden uzaklaşmak durumunda kalması, kontrolü kaybetmesine neden olacaktır. Ayrıca TBMM'nin ve devlet dairelerinin Kayseri'ye taşınması fikrini reddetmesi hem ordumuzda hem de Türk milletinde yeniliyoruz, geri çekiliyoruz algısının oluşmasını önleyerek Mustafa Kemal'in liderlik vasfının ne kadar önemli olduğunu ortaya koymuştur.

Her ne kadar ordumuzun Sakarya Irmağı'nın doğusuna çekilmesi askeri strateji olarak önemli bir taktik olsa da bu durum gerek TBMM'de gerekse ülke içinde bazı kesimleri rahatsız etmiştir. Öyle ki bu rahatsızlıklarını bazı milletvekilleri mecliste yüksek sesle dile getirmiş ve Mustafa Kemal'e karşı ağır eleştirilerde bulunmuşlardı.

"4 Ağustos'ta mecliste konuşma yapan Salahattin Bey, Mustafa Kemal Paşa'nın ülkedeki tüm askeri güçlerin başına geçmesini teklif etmişti. Mustafa Kemal Paşa'nın lehinde ve aleyhinde olan herkes bu teklife sıcak baktı. Çünkü bir sonraki savaşta da yenilgi alınırsa zanlı olarak görülen Mustafa Kemal Paşa suçlu ilan edilecek, gereken cezaya çarptırılacak böylece Paşa'nın tasfiyesi sağlanmış olacaktı” (Kurtcephe ve Beden, 2007, s. 303).

Bu koşullar altında 5 Ağustos 1921'de Meclis tarafından Mustafa Kemal'e, Başkomutanlık yetkisi verildi. Böylece Amasya Genelgesi'nden sonra askerlik görevinden ayrilan Mustafa Kemal, tekrar askerlik mesleğine dönmüş oluyordu. Başkomutanlığa getirilen Mustafa Kemal, ilk iş olarak 7-8 Ağustos 1921 'de Tekalif-i Milliye emirlerini yayımlayarak ülkede bir nevi genel seferberlik ilan etmiş oldu. "Türk halkı Tekalif-i Milliye emirleriyle, fedakarlığını ve vatanı uğruna hiçbir şeyden kaçınmayacağını gösterdiğinden savaşları ordular değil, milletler yapar gerçeğini tüm dünyanın gözleri önüne sermiştir” (Kurtcephe ve Beden, 2007, s. 305). Ancak bu ağır yenilgiden kısa bir süre sonra Yunan ordusu saldırıya geçtiği için Tekalif-i Milliye emirlerinin özellikle Büyük Taarruz'da Türk ordusuna katkı sağladığını belirtmek gerekir. 


\section{Sakarya Savaşı}

Kütahya-Eskişehir Savaşlarından sonra Ankara'nın Polatlı ilçesine kadar ilerlemiş olan Yunan ordusunun kendisine olan güveni artmış ve Sevr Antlaşması'nı yürürlüğe koymak için daha fazla cesaretlenmişlerdi. İtilaf devletleri ise II. İnönü Muharebesi'nden sonra başlattıkları geri çekilme sürecini durdurmuş, Yunanlılara özellikle silah desteğini arttırmış ve Sakarya Savaşı'nın sonucunu beklemeye başlamıştı. Hem İtilaf devletlerinin beklentilerini gerçekleştirmek hem de Megali İdea düşüncesini hayata geçirmek isteyen Yunan ordusu, Kütahya-Eskişehir Muharebelerinden 1 ay sonra her koldan büyük bir saldırıya geçmişlerdi.

"Anadolu'ya gelen Yunan ordusunun herhangi bir istilacı orduya benzemeyen avantajları vardı. Silah üstünlügüne sahipti, askerler uzun harb yıllarının yorgunu değildi hem Marmara'dan hem de Ege'den ikmal yolları açıktı ve kahir ekseriyette olmasa bile, geçtikleri yerlerde onları destekleyen Helen nüfus bulunuyordu" (Ortaylı, 2019, s. 218-219).

Ancak tüm bu olumsuzluklara rağmen Kütahya-Eskişehir Muharebeleri'nin yaşandığ1 tarihlerde Mustafa Kemal'in, I. Maarif Kongresini toplayarak yeni kurulacak devletin eğitim politikalarını belirlemeye çalışması, Türk halkının bağımsız yaşama inancına güvenen, zafere inanmış bir liderin kararlılığının göstergesidir.

Sakarya Savaşı öncesi Türk ve Yunan ordularının askeri ve silah gücüne baktığımızda Yunan ordusunun hemen her alanda üstün olduğunu görmekteyiz.

Tablo 1. Türk ve Yunan Ordularının Askeri ve Silah Gücü

\begin{tabular}{cccccccccc}
\hline & Subay & Er & Tüfek & M. Tüfek & Top & Hayvan & Araba & Kamyon & Uçak \\
\hline Türk & 5401 & 96.326 & 54.572 & 825 & 169 & 32.137 & 1.284 & - & 2 \\
Yunan & 3.780 & 120.000 & 75.900 & 2.768 & 286 & 3.800 & $?$ & 840 & 18 \\
\hline
\end{tabular}

"Bu sayılar çok çarpıcıdır. Yunanlıların elindeki makineli tüfek sayısı Türklerinkinin 3 katı, top sayısı \%59 oranından fazladır. Onlarda 84 kamyon oluşu bizde hiç olmayışı, uçak sayıları da aradaki sayı farkından öte, nitelik farkını çok iyi anlatmaktadır. Asıl çarpıcı olan er sayısıdır. Yunanistan nüfusu kabaca Türkiye'nin yarısından az olduğu halde ve Osmanlı Devleti, I. Dünya Savaşı'nda 2,5 milyon asker çıkarabilmiş iken şimdi bir ölüm kalım mücadelesinde düşman başkentin burnunun dibine gelmişken düşmandan az asker sürülebilmiştir er meydanına” (Akşin, 2019, s. 162-163).

Yunan kuvvetleri 23 Ağustos 1921 tarihinde ellerindeki tüm olanakları kullanarak saldırıya geçti. Ancak Mustafa Kemal'in önderliğinde Türk ordusu savaş tarihinde eşine az rastlanır bir savunma taktiği izlemiştir. Mustafa Kemal'in askerlerine vermiş olduğu "Hattı müdafaa yoktur, sathı müdafaa vardır. O satıh bütün vatandır, vatanın her karış toprağı vatandaşın kanı ile 1slanmadıkça düşmana terk olunamaz" emir ile Türk askerlerinden kanının son damlasına kadar vatanı için savaşmasını istemiştir. Şiddetli ve çetin mücadeleler sonucunda Türk ordusu, 10 Eylül 1921 tarihine kadar bir vatan savunması yapmış ve bu tarihten itibarende taarruz durumuna geçerek Yunan ordusunu 13 Eylül 1921 tarihine kadar tekrar Sakarya ırmağınının doğusuna geri çekilmek zorunda bırakmıştır. "23 Ağustos ile 13 Eylül arası, yani 22 gün 22 gece süren savaş 900 yıllık Türkiye tarihi açısından en kanlı ve en inatçı direnişti. Fatihlerin torunları ana yurdu savunmayı da bilmişti” (Ortaylı, 2019, s. 218).

\section{Sakarya Savaşı’nın Sonuçları ve Türk Tarihindeki Önemi}

“Bugünkü Türkiye'nin doğuşu sözünü kullanmak için öteki Ağustos’u beklemiyorum. Çünkü biz Sakarya zaferi ile artık kurtulacağımıza inanmıştık. Avrupa devletleri için dahi başkent 
İstanbul değil, Ankara idi” (Atay, 1980, s. 301). Sakarya Savaşı'nda gösterilen üstün başarıya ve elde edilen zafere dair Falih Rıfkı Atay'ın da belirttiği gibi Kurtuluş Savaşı ve Türk halkının geleceğini belirleyen dönüm noktası Sakarya Savaşı'dır denilebilir.

Yeni Türk devletinin kurtuluşunda siyasi, sosyal ve diğer alanlarda yaptığı etki ile büyük rol oynayan Sakarya Savaşı, Türk ordusunun büyük bir kahramanlık destanı yazdığı bunun yanında çok ciddi kayıpların da verildiği bir savaştır. Andre Mango bu kayıpları şöylr ifade etmektedir: "Türk ordusunun ciddi kaybı ise, çoğu eğitimlerini yeni tamamlamış genç subaylardı. Ordudaki toplam subay sayısı 5000'den biraz fazlaydı ve Sakarya Savaşı'nda 300'ü ölmüş, binden fazlası yaralanmıştı. Mustafa Kemal meclise bunun bir "zabit muharebesi" olduğunu söyleyecekti" (Mango, 2000, s. 312). Sakarya Savaşı'nın iç ve dış politikada çok önemli sonuçları ortaya çıkmıştır.

\section{Sakarya Savaşı'nın Ülkedeki Etkileri}

Mustafa Kemal'in Kurtuluş Savaş'ını Türk halkının desteğiyle kazanılabileceği düşüncesine karşın İstanbul Hükümeti ve İttihatçılar bu inanaça sahip değildi. Özellikle İstanbul Hükümeti ve yandaşları manda ve himaye düşüncesine kapılarak teslimiyetçi bir tutum izlemişlerdir. Hatta İstanbul Hükümeti'nin iç işleri bakanı Ali Kemal Bey; 'Padişahtan sonra yegâne temsilci İngilteredir.' sözüyle nasıl bir teslimiyetçi bir anlaşta olduğu belirtmiştir. TBMM'ye ve Mustafa Kemal'e güvenilmemiş Kurtuluş Savaşına inanılmamış tek çareyi büyük devletlerin hegomonyasına girmemiz gerektiğini dile getirmişlerdir.

"Sakarya zaferiyle dost ve düşman herkes, demokratik-ulusçu hareketin, TBMM hükümetinin gücünü anlamış oldu. Atatürk’ün önderliği de perçinlendi” (Akşin, 2019, s. 165). KütahyaEskişehir Muharebelerinden sonra Mustafa Kemal'e, Başkomutanlık yetkisinin verilmesini desteklerken aslında onun başarısız olacağını düşünen ve çoğunlığu ittahatçılardan oluşan muhalif kesimi de bu başarı karşısında etkisizleştirmiştir. Onlar da milli mücadele süresince Mustafa Kemal'i destekleme kararını aldılar ve Atatürk'ü birleştirici ve bütünleştirici yönüylü bir lider olarak kabul ettiler. Sakarya zaferindenden sonra türk halkının TBMM' ye ve Mustafa Kemal'e olan inancı artmış, bağımsız ve özğür yaşanabilecek günlerin yakın olduğu duygusu topluma yerleşmiştir.

"Sakarya Savaşı kazanılmış, Mustafa Kemal Anadolu hareketinin lideri olduğunu iç ve dış tüm unsurlara ispat etmiş̧ir. Enver Paşa'yı bir nevi yedek güç olarak elinde tutan Sovyetler, ondan desteklerini çekmişlerdir. Anadolu' daki İttihatçılar da artık Mustafa Kemal'le çalışmak mecburiyetini anlamışlar ve Enver Paşa'ya Anadolu'ya girmemesi için öğütler vermeye başlamışlardır” (Avcı, 2013, s. 75).

Mustafa Kemal'in Sakarya Savaşı'nda gösterdiği askeri deha ve vatan uğruna yaptığı mücadeleden dolayı TBMM tarafından, kendisine Gazilik unvanı ve Mareşallik rütbesi verilmiştir (19 Eylül 1921).

FalihRıfkı Atay bu savaşı şöyle dile getirmiştir:

"Sakarya zaferi ile "Gazi ve Müşir" Mustafa Kemal Paşa, tam otoritesini elde etmiştir. Biraz sonra Mecliste "Müdafaa-i Hukuk" grubu adı ile kendi partisini kuracaktır. Artık bir yeni devlet vardır. Onun başında bulunan adam da Mustafa Kemal'dir. Bu olup bittiyi içlerine sindiremeyenler çoktur ve durmaksızın bozgunculuk firsatı arayacaklardır ama Mustafa Kemal eskisinden çok daha kolayca bu muhalefetleri önleyecektir. Asıl büyük kriz atlatılmıştır” (Atay, 1980, s. 295). 


\section{Sakarya Savaşı'nın Uluslararası Sonuçları}

Kütahya- Eskişehir Muharebesimden sonra itilaf devletlerinin Yunan kuvvetlerine duydukları güven artmıştı.

İngilizler, Yunanlıların artık Serv Antlaşması ile yetinmeyeceğini ifade ederek Yunan kuvvetlerine olan desteklerini iyice arttırmışlardı. Yunanlıların Türk ordusunu yeneceği umuduna kapılmışlard. Fransızlar ise Kütahya- Eskişehir Muharebesimden sonra geri çekilmeyi durdurup TBMM hükümetiyle yapacakları antlaşmayı bir süre ertelediler. Türk ordusunun Yunan kuvvetlerini yenecek güçte olmadığını düşünüyorlardı. Bu dolayı güneyde işkal ettikleri bölgeleri terketmeyip bu bölgelerin kendilerinde kalacağını umut ediyorlardı.

İtalyanlar mültefikleriyle yaşadıkları sorunlara rağmen onlar da Kütahya- Eskişehir Muharebesimden sonra bir beklenti içerisine girerek inünö savaşlarından sonra başlattıkları geri çekilme faaliyetlerine ara verereksavaşın sonucunu beklediler. Kurtuluş savaşı süresince TBMM'yi detekleyen Sovyet Rusyası Anadolu hareketine hep bir kuşkuyla kuşkuyla bakmışlardır. Özellikle Kütahya- Eskişehir Muharebesinin kaybedilmesinden sonra bu kuşkuları artmıştır. Öyleki TBMM'ye yaptıkları yardımlar Sakarya Savaşı'na kadar çok büyük yardımlar olmamıştır.

Türk ordususun Sakarya Savaş'ını kazanmasından sonra itilaf devletlerinin Yunan kuvvetlerine bakışı tamamen değişmiştir. Umutlar yerini hayal kırıklıklarına bırakmıştır. İtilaf devletleri TBMM' ye karşı izledikleri politikayı değiştirmek zorunda kaldılar. Fransa ile 20 Ekim 1921'de Ankara Antlaşması imzalanmış ve Güney cephesi de resmen kapanmıştır. Fransa, TBMM Hükümeti'ni resmen tanıyıp, İngiliz-Yunan ittifakından ayrılmıştır. Bu nedenle İngiltere tarafından protesto edilmiştir. İtalyanlar Anadolu'dan tamamen çekilmiştir. İngilizler, Malta'daki tutukları serbest bırakmıştır. Ukrayna ile dostluk antlaşması imzalanmış (2 Ocak 1922) ve TBMM'nin varlığını bir devlet daha resmen tanımıştır.

Sovyetler Birliği Enver Paşaya olan umutlarını tamamen kesmiştir. TBMM'ye yaptıkları yardımları iyice artırdılar. Kendisine bağlı Gürcistan, Azerbaycan ve Ermenistan ile Kars Antlaşması imzalanmıştır (13 Ekim 1921). Bu antlaşmaya göre; Nahçivan bölgesine muhtariyet verilmiştir. Batum, Gürcistan'a iade edilecek, Kars ve Ardahan Türkiye'de kalacaktır.

Sakarya Savaşı'nın önemine dair uluslararası alanda da bazı önemli düşünürlerin görüşlerini de şöyle ifade edebiliriz. John Deny’e göre: “Millî Mücadelenin ve Türklerin Marne’1 olan bu muharebelerin ruhu, Mustafa Kemal olmuştur" sözü ile bir Fransızın Sakarya zaferini, Fransızların I. Dünya Savaşı'nda Almanlara karşı kazandığı büyük bir savunma zaferine benzetmesi Sakarya Savaşı'nın büyüklüğünü ve önemini belirtmesi açısından dikkakte değerdir. İngiliz tarihçi Arnold Toynbee'ye göre: “Sakarya Savaşı, içinde yaşadığımız yüzyıl tarihinin en büyük savaşlarından biridir" sözü ile Sakarya Savaşı'nın milletlerin kaderini değiştiren önemli savaşlardan biri olduğunu ifade etmesi açısından tarihi bir gerçekliği dile getirmiştir. Amerikalı bir gazeteci olan Clair Price'de Sakarya Savaşı için “Tarih bir gün Sakarya kıyılarında cereyan eden ve çok kimsenin bilmediği bu savaşı devrimizin en büyük olaylarından biri olarak kaydedecektir" diyerek Sakarya Savaşı'nın uluslararası alandaki önemini de ifade etmiştir (Eroğlu, 1977, s. 136).

Sakarya Savaşı ile Yunan ordusu yenilgiye uğratılmış, Yunanlılar saldırı gücünü kaybederek savunmaya çekilmek zorunda kalmıştır. Sakarya Savaşı, Şark meselesini gerçekleştireceklerini düşünen İtilaf devletlerinin hayallerinin boşa çıkması ve II. Viyana Kuşatması'ndan itibaren sürekli geri çekilen Türklerin artık taarruz durumuna geçecek olması, Yunan Megali idea 
düşüncesini sona erdirmesi yanında yaratmış olduğu iç ve dış sonuçlar itibariyle Türk tarihinin önemli zaferlerinden biridir.

\section{YÖNTEM}

Sakarya Savaşı hakkında öğretmenlerimizin hazır bulunuşluk düzeylerini ve bu konunun nasıl verilmesi gerektiğini ölçen açık uçlu sorulardan oluşan bir nitel çalışma gerçekleştirilmiştir. Çalışma grubu Bolu ili Merkez ilçesi 15 Sosyal Bilgiler öğretmeniyle sınırlıdır. Öğretmenlerin 10'u erkek 5'i kadındır.

$\mathrm{Bu}$ bölümde anket formundaki sorulara, Sosyal Bilgiler öğretmenlerinin vermiş olduğu cevaplardan sağlanan bulgular ve yorumları yer almaktadır.

\section{BULGULAR VE YORUMLAR}

Öğretmenlerden Sağlanan Bulgular ve Yorumlar

Tablo 2. 1. Soru; Sakarya Savaşı'nın Türk tarihi içerisindeki önemi nedir?

\begin{tabular}{lcc}
\hline & f & \% \\
\hline Bir dönüm noktasıdır & 7 & 45 \\
II. Viyana'dan sonra geri çekilmeye son veren savaştır & 5 & 34 \\
Birlik ve beraberliği sağlamıştır & 1 & 7 \\
Psikolojik üstünlüğü sağlamıştır & 1 & 7 \\
Var olma savaşıdır & 1 & 7 \\
\hline
\end{tabular}

$\mathrm{Bu}$ soruya; Öğretmenlerin vermiş olduğu cevaplar incelendiğinde; 7 öğretmen Sakarya Savaşı'nın bir dönüm noktası olduğunu, 5 öğretmen Sakarya Savaşı'nın Viyana Kuşatması'ndan itibaren süregelen geri çekilmeye ve savunmaya son verdiğini, 1 öğretmen Sakarya Savaşı'nın birlik ve beraberlik sağladığını, 1 öğretmen Sakarya Savaşı ile Türklerin psikolojik üstünlük sağladığını, 1 öğretmen Sakarya Savaşı'nın var olmayı sağladığını belirtmiştir. Cevaplara baktığımızda öğretmenlerin Sakarya Savaşı'nın Türk tarihi içindeki öneminin farkında oldukları görülmektedir.

Tablo 3. 2. Soru; Sakarya Savaşı'nın Sosyal Bilgiler Öğretimi açısından önemi nedir?

\begin{tabular}{lcc}
\hline & $\mathbf{f}$ & $\mathbf{\%}$ \\
\hline Vatan ve millet sevgisi gibi milli duygular sağlamıştır & 9 & 61 \\
Öğrencilere vatanın kurtulmasındaki zorlukları öğretir & 3 & 21 \\
Geri çekilmeye son vermiştir & 1 & 6 \\
Sosyal Bilgiler dersini sevdirmiştir & 1 & 6 \\
Psikolojik üstünlüğü sağlamışır & 1 & 6 \\
\hline
\end{tabular}

$\mathrm{Bu}$ soruya; Öğretmenlerin vermiş olduğu cevaplar incelendiğinde; 9 öğretmen Sakarya Savaşı'nın vatan ve millet sevgisi gibi milli duygular sağladığını, 3 öğretmen Sakarya Savaşı'nın öğrencilere vatanın kurtulmasındaki zorlukları öğrettiğini, 1 öğretmen Sakarya Savaşı'nın geri çekilmeyi sağladığını, 1 öğretmen Sakarya Savaşı'nın Sosyal Bilgiler dersini sevdirdiği, 1 öğretmen Sakarya Savaşı ile psikolojik üstünlük sağlandığını belirtmiştir. 
Tablo 4. 3.Soru; 8. Sınıf İnkılap Tarihi ve Atatürkçülük dersinde Sakarya Savaşı hakkında yeterli bilgi veriliyor mu?

\begin{tabular}{lcc}
\hline & f & \% \\
\hline Yeterli kadar bilgi yer veriliyor & 11 & 73 \\
Yeterli kadar bilgi yer verilmiyor & 4 & 27 \\
\hline & $\mathbf{1 5}$ & $\mathbf{1 0 0}$ \\
\hline
\end{tabular}

$\mathrm{Bu}$ soruya; Öğretmenlerin vermiş olduğu cevaplar incelendiğinde; 11 öğretmenin Sakarya Savaşı ile ilgili derslerde yeteri kadar bilgiye yer verildiğini, 4 öğretmen ise Sakarya Savaş1 ile ilgili derslerde yeteri kadar bilgiye yer verilmediğini belirtmiştir. Öğretmenlerin cevaplarına baktığımızda Sakarya Savaşı ile ilgili derslerde bilgi verilirken daha çok kitaplardaki bilgilerle sınırlı kalındığı, bu zaferin sözlü ve yazılı eserlerle desteklenmesi gerektiğini belirtmişlerdir. Öğretmenlerimiz konuyu müze gezileriyle de zenginleştirmeliler.

Tablo 5. 4.Soru; 8. Sınıf İnkılap Tarihi ve Atatürkçülük ders kitabında Sakarya Savaşı'nın Türk tarihi açısından önemi yeterince vurgulaniyor mu?

\begin{tabular}{lcc}
\hline & $\mathbf{f}$ & $\mathbf{\%}$ \\
\hline Önemi yeterince vurgulaniyor & 9 & 60 \\
Önemi yeterince vurgulanmiyor & 5 & 33 \\
Önemi k1smen vurgulaniyor & 1 & 7 \\
\hline & $\mathbf{1 5}$ & $\mathbf{1 0 0}$ \\
\hline
\end{tabular}

$\mathrm{Bu}$ soruya; Öğretmenlerin vermiş olduğu cevaplara incelendiğinde; 9 öğretmen Sakarya Savaşı'nın ders kitabında Türk tarihi açısından öneminin vurgulandığını, 5 öğretmen Sakarya Savaşı'nın ders kitabında Türk tarihi açısından öneminin yeteri kadar vurgulanmadığını, 1 öğretmen Sakarya Savaşı'nın ders kitabında Türk tarihi açısından öneminin kısmen vurgulandığını belirtmiştir. Öğretmenlerin cevaplarına baktığımızda; öğretmenlerin büyük bir oranda fikir ayrılığı yaşadıklarını görmekteyiz.

Tablo 6. 5.Soru; Sınıf İnkılap Tarihi ve Atatürkçülük ders kitabında Türk tarihine damga vurmuş diğer savaşlar kadar Sakarya Savaşı’na önem veriliyor mu?

\begin{tabular}{lcc}
\hline & $\mathbf{f}$ & $\mathbf{\%}$ \\
\hline Diğer önemli savaşlar kadar önemseniyor & 7 & 47 \\
Diğer önemli savaşlar kadar önemsenmiyor & 8 & 53 \\
\hline
\end{tabular}

$\mathrm{Bu}$ soruya; Öğretmenlerin vermiş olduğu cevaplara incelendiğinde; 8 öğretmen Sakarya Savaşı'nın Türk tarihindeki diğer önemli savaşlar kadar önemsenmediğini, 7 öğretmen Sakarya Savaşı'nın Türk tarihindeki diğer önemli savaşlar kadar önemsendiğini belirtmiştir. Öğretmenlerin cevaplarına baktığımızda öğretmenlerin yarısına yakını Sakarya Savaşı gibi önemli bir savaş ile ilgili ders kitabındaki eksikleri görmediklerini söyleyebiliriz. Bu eksikliğin de öğretmenlerin mesleki eğitimleri sırasında konuyla ilgili yeterli donanıma sahip olmadıkları sonucunu ortaya koymaktadır.

Tablo 7. 6.Soru: Sakarya Savaşı ile ilgili yeteri kadar doküman olduğunu düşünüyor musunuz?

\begin{tabular}{lcc}
\hline & $\mathbf{f}$ & $\boldsymbol{\%}$ \\
\hline Dokümanların yeterlidir & 5 & 33 \\
Dokümanların yetersizdir & 10 & 67 \\
\hline & $\mathbf{1 5}$ & $\mathbf{1 0 0}$ \\
\hline
\end{tabular}

Bu soruya; Öğretmenlerin vermiş olduğu cevaplara incelendiğinde; 10 öğretmen dokümanların yetersiz olduğunu belirtmiştir. Dokümanların yetersiz olduğunu belirten 10 öğretmenden 8 
tanesi eksik olan materyalleri şöyle belirtmiştir. Görsel materyal eksikliği diyen 3 kişi, Özgün eser eksikliği diyen 2 kişi, Maneviyatı geliştiren eser eksikliği diyen 1 kişi, Sözlü tarih eksikliği diyen 1 kişi, Bilinçli öğretmen ve bilinçli öğrenci yetiştirmesini sağlayan doküman eksikliği var diyen 1 kişi bulunmaktadır. 2 öğretmen hangi dokümanların eksik olduğunu belirtmemiştir. 5 öğretmen dokümanların yeterli olduğunu belirtmiştir. Dokümanların yeterli olduğu belirten öğretmenler, dokümanlara ulaşma sorunu olduğunu da vurgulamışlardır.

Tablo 8. 7.Soru Sakarya Savaşı'nda Türk milletinin sergilediği duygu ve davranışlar öğrencilere yeteri kadar aktarlabiliyor mu?

\begin{tabular}{lcc}
\hline & f & \% \\
\hline Yeteri kadar aktariyor & 2 & 14 \\
Kismen aktariliyor & 2 & 14 \\
Yeteri kadar aktarmiyor & 11 & 72 \\
\hline & $\mathbf{1 5}$ & $\mathbf{1 0 0}$ \\
\hline
\end{tabular}

$\mathrm{Bu}$ soruya; Öğretmenlerin vermiş olduğu cevaplar incelendiğinde; 11 öğretmen duygu ve düşüncelerin yeteri kadar aktarılmadığını belirtmiştir. Duygu ve davranışların öğrencilere yeteri kadar aktarılmadığını belirten 11 öğretmenden 8 tanesi eksiklikleri şöyle belirtmiştir. Fedakarlıklar aktarılmamış diyen 4 kişi, duygu ve düşünceler daha vurgulu olmalı diyen 3 kişi, sadece bilgi düzeyinde öğrenim verilmesi diyen 1 kişi olarak belirlenmiştir. 3 öğretmen ise hangi duygu ve davranışları aktarılmadığını belirtmemiştir. Duygu ve davranışlar öğrencilere kısmen aktarılabiliyor diyen 2 kişidir. 2 öğretmenden 1 tanesi sınav kaygısını, 1 tanesi ise; bazı öğrencilerin duygu ve davranışı yeterince alamadığını vurgulamışlardır. Duygu ve davranışlar öğrencilere yeteri kadar aktarılıyor diyen 2 kişidir. Öğretmenlerimizin yöntem konusunda sıkıntı yaşadıklarını söyleyebiliriz.

Tablo 9. 8.Soru; 8. Sınıf İnkılap Tarihi ve Atatürkçülük ders kitabında Sakarya Savaşı'nın sonuçlarının İtilaf devletlerinin politikalarına olan etkisi yeterince aktarılabiliyor mu?

\begin{tabular}{lcc}
\hline & $\mathbf{f}$ & $\boldsymbol{\%}$ \\
\hline Evet & 8 & 56 \\
Hayir & 7 & 44 \\
\hline
\end{tabular}

Bu soruya; Öğretmenlerin vermiş olduğu cevaplara incelendiğinde; 8 öğretmen evet demişken, 7 öğretmen hayır demiştir. Evet diyen öğretmenlerden 3 tanesi İtilaf devletlerinin TBMM ile barış yapmak zorunda kaldığı vurgulamışlardır. Hayır diyen 7 öğretmenden 3 tanesi ise; İtilaf devletlerinin değişen politikaları yeterince vurgulamadığını belirtmiştir.

Tablo 10. 9.Soru; Eğer Sakarya Savaşı'na gerekli önemin verildiğini düşünüyorsanız öğrencilerde ne gibi istendik davranışlar görülebilir? Bu konudaki düşünceleriniz nelerdir?

\begin{tabular}{lcc}
\hline & f & \% \\
\hline Vatan ve millet sevgisi gibi milli duygular sağlar & 2 & 13 \\
Birlik ve beraberliği sağlar & 3 & 20 \\
Fedakarlık durgusunu geliştirir & 1 & 7 \\
Milliyetçilik duygusunu geliştirir & 3 & 20 \\
Tarih bilincini geliştirir & 2 & 13 \\
Bağımsızlık duygusunu geliştirir & 1 & 7 \\
İstendik davranışlar olamaz & 3 & 20 \\
\hline
\end{tabular}

Bu soruya; Öğretmenlerin vermiş olduğu cevaplara incelendiğinde; 12 öğretmen öğrencilerde istendik davranışların gelişebileceğini düşünürken 3 öğretmen ise; istendik davranışların 
olamayacağını belirtiğini görmekteyiz. Olumsuz düşünen öğretmenler, öğrencilerin yaşlarının küçük olduğunu ve empati duygusunun gelişmediğini düşünmektedirler.

\section{SONUÇ VE TARTIŞMA}

Yapılan çalışmada elde edilen bulgular kendi içinde değerlendirilmiştir. Bu değerlendirmeleri 1şı̆̆ında hem tarihi süreç hem de öğretmenlerin verdikleri cevaplar birlikte göz önüne alınardığında ulaşılan sonuç: Sakarya Savaşının da Çanakkale ya da Malazgirt savaşları gibi Türk tarihinin bir dönüm noktası olduğudur. Bu sonuçtan yola çıkarak, Sakarya Savaşı da milli birlik ve berabarlik duygusunun verilmesi amacı doğrultusunda ders programlarında hak ettiği yeri almalı, yeni Türk devletinin kuruluşunda ve Türk milletinin bağımsız yaşamasında en önemli aşamalardan biri olduğu vurgulanmalıdır.

Sakarya Savaşı'nın kazanılması sürecinde yaşanan olaylar ve "Hattı müdafaa yoktur sathı müdafaa vardır" aşamasına gelinmesi bu aşamada yapılan milli fedakarlıklar gençlerin milli bilincinin oluşmasına önemli katkı sağlayacaktır.

\section{KAYNAKÇA}

Akşin, S. (2019). Kısa Türkiye Tarihi, 26. Basım, İstanbul.

Akçura, Y. (2016) Şark Meselesine Dair Ve Eski "Şuray-I Ümmet'te Çıkan Makalelerimden. İstanbul.

Artuç, İ. (1985). Büyük Dönemeç Sakarya Meydan Muharebesi. İstanbul.

Atay, F. R. (1080). Çankaya. İstanbul.

Avcı, C. (2013). Saltanattan Cumhuriyete Demokratik Olgunlaşma Tarihi (1789-1938). İstanbul.

Aydemir, Ş. S. (2011). Tek Adam, C. I, İstanbul.

Belen, F. (2014). Türk Kurtuluş Savaşı. İstanbul.

Eroğlu, H. (1977). Türk Devrim Tarihi, Ankara.

Görgülü, İ. (1993). On Ylllık Harbin Kadrosu 1912-1922. Ankara.

Hourı, P. (2016). Türkiye Nasıl Paylaşıldı? Kaynarca Muahedesi'nden Son Felaketimize Kadar Şark Meselesi. İstanbul.

Kinross, L. (2008). Osmanll-İmparatorluğun Yükselişi ve Çöküşü. İstanbul.

Kocatürk, U. (1999). Atatürk'ün Fikir Ve Düşünceleri. Ankara.

Kurtcephe, İ. ve Beden, A. (2007). Türkiye Cumhuriyeti Tarihi, Ankara.

Mango, A. (2000). Atatürk. İstanbul

Ortaylı, İ. (2019). Gazi Mustafa Kemal Atatürk, 8. Baskı. İstanbul.

Özsoy, O.(1999). Kurtuluş Savaşı'nin Perde Arkası. İstanbul.

Tekinoğlu, H. (2015). Selçuklu Tarihi. İstanbul.

Yalçın, D., Akbıyık, Y. ve Eraslan, C. (2000). Türkiye Cumhuriyeti Tarihi-I. Ankara, 2000. 


\section{EXTENDED ABSTRACT}

\section{Social Studies Teachers' Views About the Importance of The Battle of Sakarya and Its Place in the Textbooks}

Important events that have changed the fate of societies exist throughout the history. Such events may include an invention of an inventor, birth of a leader who changed the course of the history or a great war that brought the societies to the brink of extinction. Wars have various impacts on nations in many different ways such as socially, politically, economically and psychologically. Many states that have been established since the Sumerians, which were accepted to be the first true state in history, have fought important wars. Some of those wars have had a great positive or a negative impact on both humanity and nations. Similarly, in Turkish history there exist important developments that have influenced the period these developments occurred and additionally shaped the present day. Some of the important examples are; the Battle of Talas, which started the process of conversion of the Turks to Islam, the Dandanakan War, which paved the way to the foundation of the Seljuk State, the Battle of Manzikert, which opened the door of Anatolia to Turks, the Conquest of Istanbul, which opened a new age and closed one, and the Battle of Gallipoli (Çanakkale), which significantly changed the course of the First World War.

In this study, the five battles that affected the fate of the turkish nation are addressed and the Battle of Sakarya is discussed in details. The Battle of Sakarya, which had international outcomes as well, is a milestone in turkish history for ceasing the influence of the European states in the Eastern Question that involves the activities to expel the Turks from Anatolia and the Balkans, proving the failure of the activities of the Entente States together with Greece in the enforcement of the Treaty of Sevres, solidifying the belief that the Turkish National Movement would succeed eventually and the acceptance of the indisputable leadership of Mustafa Kemal both on national and international scale. The wars won by such important and total struggle can make a significant contribution to the development of the sense of unity and solidarity of a nation and to the love of homeland. For these reasons, the Battle of Sakarya has significant potential contributions toward ensuring the unity and solidarity of Turks due to the enormous impacts it has made in Turkish history. Based on the fact that important topics such as the Battle of Sakarya should find their rightful place in history education and be discussed more rigorously, we examined how the topic of the Battle of Sakarya has been covered in the syllabus of the course "Turkish Republic Revolution History and Kemalism for 8th grade" and try to identify the readiness level of the teachers in the class when they discussed the topic together with their point of views on the topic.

We carried out a qualitative study consisting of 9 open-ended questions in order to identify the readiness level of teachers on the Battle of Sakarya and how the topic has been discussed. In our survey, 3 questions were opinion questions that require long answers. The remaining 6 questions needed short or one-sentence answers. The subject group was limited to 15 Social Studies teachers working in the central district of Bolu province. 10 of the teachers were male and 5 were female.

The findings obtained in the study were evaluated all together. A general comment in the light of these evaluations is that the subject teachers are aware of the historical significance of the Battle of Sakarya and its impact on the new generation to form a national identity. Contrary to this finding, we also found out that despite its importance discussed above, the Battle of Sakarya 
has a limited place in the curriculum that deprived the students to gain detailed knowledge about the battle. Another important point reached in the study was that the teachers experience problems in accessing reliable resources that cover the Battle of Sakarya. We also concluded that even though some particular wars and battles that are important for Turkish history were covered in details, the Battle of Sakarya is not given the necessary attention.

Considering the outcomes of the Battle of Sakarya in the national and international arena, together with answers given by the subject teachers, we can conclude that the Battle of Sakarya is a turning point in Turkish history, such as the Battles of Manzikert and Gallipoli. Based on this, we believe that the Battle of Sakarya should take its rightful place in the curriculum in order to give a sense of national unity and solidarity, and it should be emphasized that it is one of the most important stages in the establishment of the new Turkish state and the independence of Turkish nation. The experiences gained and sacrifices made during the Battle of Sakarya together with the well-known quote stated by Atatürk that imprinted on our memories "There is no defense line, but a defense territory, and that territory is the whole of the motherland. Not even an inch of the motherland may be abandoned without being soaked in the blood of her citizens." will contribute substantially to the formation of the national consciousness and identity in youth. 